\title{
DETERMINAÇÃO DE PARÂMETROS HEMATOLÓGICOS EM CODORNAS (Coturnix coturnix) DE CRIAÇÃO INDUSTRIAL .
}

R. LOCATELLI-DITTRICH ${ }^{1}$; G.P. PERAZZOLI ${ }^{2}$; E.M.S. SCHMIDT ${ }^{3}$; A.L. FRANÇA NETO ${ }^{4}$; M.E. SAITO ${ }^{2}$; M. ANDRI ${ }^{5}$; I.R. MATTOS $;$; P. PIOVESAN ${ }^{7}$

${ }^{1}$ Professora do Departamento de Medicina Veterinária - Universidade Federal do Paraná. ${ }^{2}$ Acadêmicos do Curso de Medicina Veterinária / Bolsistas do Programa UFPR- Tesouro Nacional. ${ }^{3}$ Mestranda do Curso de Pós-Graduação em Ciências Veterinárias - Universidade Federal do Paraná. ${ }^{4}$ Médico Veterinário de Avicultura da Perdigão Agroindustrial S.A., Videira/SC. ${ }^{5}$ Acadêmica do Curso de Medicina Veterinária/ Monitora da Disciplina de Semiologia e Laboratório Clínico Veterinário. ${ }^{6}$ Supervisor de Área - Avicultura da Perdigão Agroindustrial S.A., Videira/SC. ${ }^{7}$ Supervisor de Setor - Codornas da Perdigão Agroindustrial S.A., Videira/SC.

A criação de codornas sobressai na atualidade como fonte alternativa de proteína de origem animal, sendo os seus produtos apreciáveis em todo mercado nacional. Contudo, a espécie é acometida por algumas doenças que contribuem para consideráveis perdas econômicas no plantel. No Brasil, são escassos os estudos hematológicos nesta espécie com a finalidade de estabelecer parâmetros referenciais. Como parte de um projeto de pesquisa destinado à obtenção de parâmetros laboratoriais de codornas de criação industrial, foram realizados eritrogramas e a determinação de proteína plasmática de 22 codornas (Coturnix coturnix ) da categoria de terminação, provenientes de granjas da cidade de Videira - SC. As colheitas de sangue foram realizadas através de punção cardíaca e as amostras acondicionadas em frascos com anticoagulante EDTA. Para a contagem total de eritrócitos em câmara de Neubauer, foi utilizado o método do Azul de Toluidina 0,01\%. A hemoglobina foi determinada com auxílio de kit comercial e leitura espectrofotométrica após centrifugação, e o hematócrito pela técnica do microhematócrito. A proteína plasmática total foi determinada em refratômetro. As médias e os desvios padrão encontrados foram: eritrócitos (x $\left.10^{6} / \mu \mathrm{l}\right) \rightarrow 2,00$ e 0,34 ; hemoglobina $(\mathrm{mg} / \mathrm{dl}) \rightarrow 11,68$ e 1,68; hematócrito $(\%) \rightarrow 39,64$ e 4,3; proteínas plasmáticas totais $(\mathrm{mg} / \mathrm{dl}) \rightarrow 3,83$ e 1,06 . Os parâmetros laboratoriais de referência contribuem para auxiliar no diagnóstico de estados patológicos e para avaliação do estado nutricional e metabólico dos animais. 